for solid waste management, and "on a misreading of the 'stability' of glass under repository conditions."

It recommends that, as an alternative to glass, cement-based composites and low-temperature ceramics should be researched vigorously as the prime candidates for solidification of DoE wastes, an approach given wide publicity by Professor A. E. Ringwood of the Australian National University last month, and which has been closely studied in the US for a number of years.

Such challenges to the conventional scientific wisdom on nuclear waste disposal, many of which have resulted from the growing involvement of geochemists into a field previously dominated by physicists and engineers, has led the Department of Energy to broaden considerably the scope of its research options. In addition to salt formations, for example, there are now active programmes investigating the suitability of other geological media such as basalt, granite and shale.

At the same time, the department is adopting a more holistic approach to the waste management problem. Dr John Deutch, head of the Department's Office of Energy Research, told a Senate committee two weeks ago that the selection of a particular site for its environmental qualities could be more important than the choice of a particular medium.

"It is very important that the entire environment of a site is evaluated, in particular its chemical, geological and hydrographical characteristics", Dr Deutch told the committee, adding that "the problems of finding a site, even for just assessing, are formidable."

Such problems are illustrated by the Department's current plans to construct a Waste Isolation Pilot Plant (WIPP) in salt beds near Carlsbad in New Mexico. The nuclear industry is keen that the department should move ahead rapidly with its plans for WIPP, thus demonstrating that the safe disposal of radioactive waste is feasible.

However, local environmental groups in New Mexico, drawing attention to the USGS and other reports which point to current gaps in knowledge about the behaviour of salt - as well as the problems of later retrievability of the waste from salt deposits-are challenging the department's plans on the grounds that other geological media might be more appropriate for such a demonstration plant.

Both the frustration of the nuclear industry, and the concern of environmentalists, stems partly from the fact that the more research that is done into methods of waste disposal, the more scientists are realising that important gaps in knowledge still remain.

A recent report prepared by the

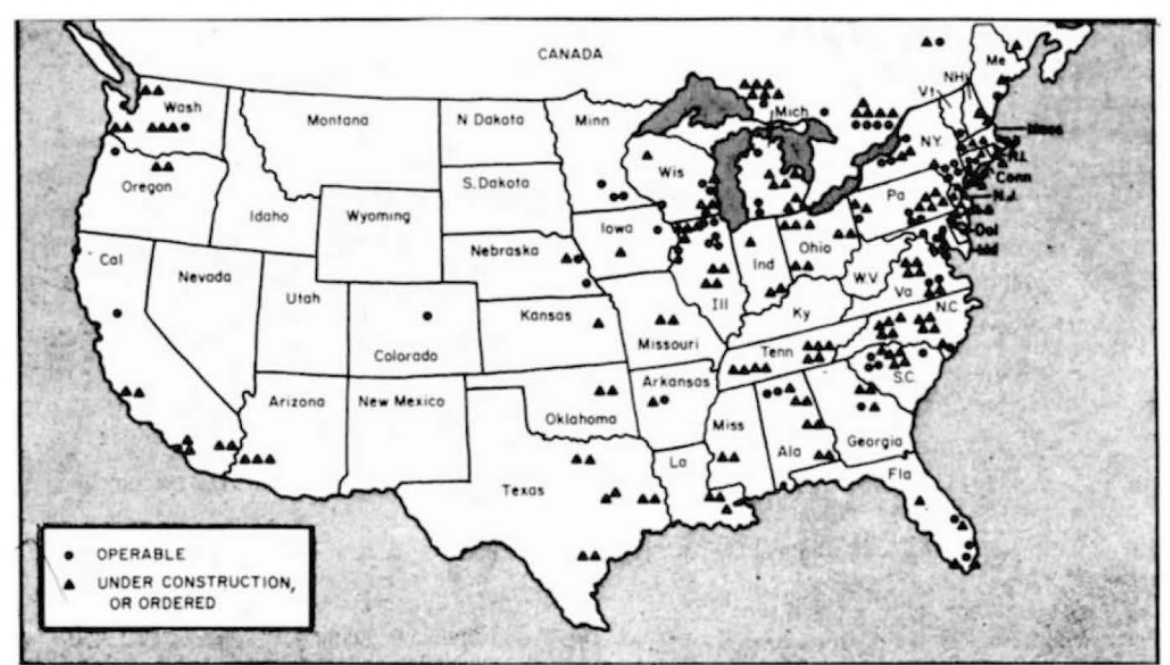

The size of the waste problem: America's nuclear reactors

Map taken from Oceanus, adapted from data supplied by Nuclear News, September 1976 and from US ERDA

Office of Science and Technology Policy for the President's Interagency Task Force, for example lists "numerous limitations of our knowledge" in hydrogeology, geochemistry and rock mechanics, "relatively young sciences with little experience in making or evaluating predictions that cover time frames even as short as a few decades".

The OSTP report adds that, despite such limitations, "we believe that such gaps in our knowledge need not rule out successful underground containment of radionuclides for periods of many thousands of years". Yet while such gaps exist, the question of the "adequacy" of proposed disposal-and even transportation-methods remains open to active debate.

It was the lack of federal regulation concerning the transportation of nuclear wastes, for example, that led the US Department of Transportation to issue a decision earlier this year supporting New York City's right to impose the ban that has prevented Brookhaven from shipping its spent fuel to South Carolina, and agreeing that, under the terms of the Hazardous Material Transportation Act, the ban could not be pre-empted by federal action.

The laboratory is at present contesting the constitutionality of the ban. "The laboratory does not acknowledge the validity of New York City's ban and New London's ordinance on the transportation of spent fuel elements through these cities", according to $\mathrm{Mr}$ Michael Goldman, an attorney for the universities which operate the laboratory. "But we would like to begin shipping spent fuel elements this fall to ensure that there is no interruption of research at the reactor."

Opponents of the ban point to a recent report from the Sandia Laboratories claiming that the transport of radioactive waste through urban areas poses a relatively low risk. Supporters, such as Friends of the Earth, claim that this study was coloured by the fact that it was commissioned by a government agency keen to validate its claims that federal legislation should pre-empt local regulations.

Some guidance will no doubt be provided by the Interagency Task Force when it presents the results of its deliberations to President Carter at the beginning of October; the Department of Transportation, for example, is preparing a study for the task force on the transportation of waste, and the Brookhaven case should figure prominently in its deliberations.

Ironically, current work at the reactor involves a variety of research projects in the health and environmental fields, including not only a study of trace elements and pollutants in the environment, but also an analysis of air samples for the New York State Department of Health.

\section{Nuclear moratorium}

WISCONSIN has become the fourth US state to place a moratorium on the future construction of nuclear power plants in the light of current uncertainty over running costs, the availability of nuclear fuels, and safety aspects of waste disposal and decommissioning.

In announcing the moratorium last Friday, the state's Public Service Commission joined similar bodies in three other states-California, Iowa and Maine-which are pressing the Federal Government for firm guidance on such issues.

Conceding that nuclear power had an "impressive record" in Wisconsin, State Governor Martin Schreiber said its performance in other states "produces doubts that it is economically preferable to other forms of energy, energy conservation and alternative renewable energy sources. 